\title{
Measurement of Lipid Peroxidation and Phenol Contents Under Heat Stress Condition in Sugarcane Genotypes
}

\author{
Syed Rizwan Abbas ${ }^{1}$, Syed Dilnawaz Ahmad Gardazi ${ }^{2}$, Syed Mubashir Sabir ${ }^{1}$, Attiya Batool ${ }^{4}$, Aourangzeb Rao ${ }^{1}$, \\ Asad Hussain Shah ${ }^{1}$, Sundas Shazad ${ }^{5}$, Rizwan Taj Khan ${ }^{4} \&$ Muhammad Rehan Abbas ${ }^{3}$ \\ ${ }^{1}$ Faculty of Agriculture, University of Poonch Rawalakot, Pakistan \\ ${ }^{2}$ Vic Chancellor of University of Azad Jammu and Kashmir, Muzaffarabad A. J. K., Pakistan \\ ${ }^{3}$ Department of Computer Science, University of Azad Jammu and Kashmir \\ ${ }^{4}$ Department of Botany, University of Azad Jammu and Kashmir \\ ${ }^{5}$ Department of Biotechnology, Ayub institute Faisalabad \\ Correspondence: Syed Rizwan Abbas, Faculty of Agriculture, University of Poonch Rawalakot, Pakistan. E-mail: \\ drsyedrizwanabbas@gmail.com
}

Received: December 8, 2012

Accepted: December 27, 2012 Online Published: September 15, 2013

doi:10.5539/jas.v5n10p214

URL: http://dx.doi.org/10.5539/jas.v5n10p214

\begin{abstract}
The experiment conducted in the laboratory of Plant Breeding and Molecular Genetics, Faculty of Agriculture, Rawalakot, Pakistan. Leaves of thirteen genotypes of sugarcane used for this experiment and were treated in an oven for heat stress. The treated leaves were then used for the estimation of phenol contents and the measurement of lipid peroxidation against heat stress. Minimum moisture loosed by CPF-237 and maximum moisture loss showed by CO-1148. Maximum phenol contents were observed in S-2003-US-778 showed high results (58.78 mg $\mathrm{GAE} / 100 \mathrm{ml}$ ) and minimum were $\mathrm{Rb}-72$ and $\mathrm{CO}-1148$ showed the lowest values (36.17 and $37.5 \mathrm{mg} \mathrm{GAE} / 100 \mathrm{ml})$. The higher heat tolerance of genotype, CPF-237 related to higher membrane stability, and maintenance of high $\mathrm{fv} / \mathrm{fm}$ ratio under heat stress and lower lipid peroxidation of membranes. Hence, the relative tolerance of a genotype to heat stress as reflected by its lower lipid peroxidation, and higher membrane stability and pigment concentration, related to the levels of activity of its antioxidant enzymes. By using morphological parameters, S-2003-US-778 was significantly different from Rb-72. Based on biochemical data, the genotypes S-2003-US-778, S-2003-US-694, CPF-237 and Co-1148 are heat tolerant genotypes and thus can be successfully planted in warmer areas to alleviate the socioeconomic status of farmers.
\end{abstract}

Keywords: sugarcane, heat stress, lipid peroxidation, phenol contents, morphological parameters

\section{Introduction:}

Sugarcane (Saccharum officinarum L.) is an important cash crop of Pakistan, plays energetic role to improve economic perspective of the farmers and survival of ever-expanding sugar industry in Punjab. Pakistan is significant cane producing country and categorized fifth in world cane acreage and $15^{\text {th }}$ in sugar production (Insert Reference). Sugarcane developed on over a million hectares and delivered the raw material for Pakistan's 84 sugar mills, which contain the country's second largest agro-industry after textiles (Rehman, 2009). Thus evolution of new high cane and sugar yielding varieties and upgraded production technology i.e., Better Management Practices (BMPs) are existing need for improving livelihoods of sugarcane growers and other crops and ultimately advancement of mill owners also (Nasir, 2006; Iftikhar et al., 2010). Addition of organic matter in soil recovers the physicochemical and biological properties. Assessment of adaptation, performance of various cane selections in different ecologies, and evaluation of agronomic characters of exotic cane varieties is necessary before a variety introduced for commercial cultivation. Cane yield and sugarcane evaluation of varieties were commonly done on stalk, stalk height, and stalk girth, stalk weight and fiber contents (Akhtar et al., 2000). The major commercial sugar lands in Pakistan are all located in its Punjab and Sindh regions: an ecological zone that is often subject to fluctuating periods of drought due to insufficient and unpredictable distribution of rainfall. This poses a serious problem for sugar cane, which has a 10 to 12 -month crop cycle. When drought occurs during the formative growth phase (0-120 days after plantation) the crop experiences slow growth, which then results in low cane yield (Barnes, 1974). In order to recover sugar yields, it is necessary to develop cultivars that remain dynamic under low soil 
moisture availability. Screening for drought tolerance can be achieved by simulating moisture stress at the critical growth stage of the crop, either under controlled atmosphere conditions or under field conditions.

Little success has achieved in screening plants for drought tolerance by selection for morphological features due to genotype $\times$ environment interactions (Bendelow et al., 1955). Blum (1988) theorized that the simplest approach for drought tolerance would be to utilize the natural stress of the field environment to screen genotypes. Despite the relatively drought tolerant nature of the sugar-cane plant, varieties differ obviously in their tolerance to drought (Moore, 1987). Sugarcane varieties susceptible to drought will be wilt, with indication of reduced cane production early during drought, while tolerant varieties remain turgid, and maintain near-optimum growth for longer production (Moore, 1987). Tolerant varieties have the capability to reduce transpiration losses, while at the same time upholding adequate absorption of water from the soil.

The mechanism of the toxic consequence of organophosphate compounds involves the inhibition of acetyl-cholinesterase and other non-specific esterases through phosphorylation at the esterase centre's of the enzyme. This mechanism is the same for all insecticides of the group, irrespective of differences in their chemical structure (Lotti, 2001). The inhibition of the activity of cholinesterase enzymes reasons an increase in the level of endogenous acetylcholine in the organism and results in its binding to muscarinic and nicotinic receptors in both of the peripheral and central nervous systems. This rise in the CNS (Explain $1^{\text {th }}$ ) disturbs the balance between neurotransmitters and causes the onset of acute intoxication symptoms (Lotti, 2001). The symptoms of acute intoxication with organophosphates have well described, while the effects of chronic exposure to these compounds are not completely clear. Many authors postulate that they may have an effect on redox procedures in a number of organs, thus leading to disturbances in these procedures and causing enhancement of lipid peroxidation, both in acute and chronic intoxication by these compounds (Abdollahi, 2004; Sharma, 2005). As increased generation of reactive oxygen species and lipid peroxidation induced by these species underlies many diseases. It is extremely important to regulate the effect of organophosphate insecticides on lipid peroxidation processes (Mates, 1999; Yagi, 1987).

The objective of this study was to eliminate drought tolerant genotypes of sugarcane through heat stress. Such screening will aid in the cataloging of genotypes in the selection of commercial sugarcane cultivars. In the documentation of parents to improved genetically drought tolerance sugarcane cultivars developed for Pakistan.

\section{Materials and Methods}

\subsection{Plant Materials}

Thirteen Sugarcane genotypes have been collected from different sugarcane institutions of Pakistan and have been cultivated in the glasshouse of Faculty of Agriculture, Rawalakot.

\subsection{Morphological Parameters}

Thirteen local sugarcane genotypes namely S-2003-US-778, CPF-246, SPF-234, S-2002-US-160, CPF-237, S-2003-US-694, CO-1148, SPHS-35, S-2003-US-633, CPF-247, S-2003-US-114, CPF-238 and Rb-72 were planted in the glasshouse of Faculty of agriculture, Rawalakot. The experiment was laid out in Randomized Complete Block (RCB) Design with three replications. All agronomic practices kept normal for all the 13 genotypes. Data on plant height $(\mathrm{cm})$, number of tillers per plant, number of leaves, cane diameter $(\mathrm{cm})$, leaf area $\left(\mathrm{cm}^{2}\right)$, intermodal distance $(\mathrm{cm})$, number of nodes, collected from 10 randomly selected stalks from each replications.

\subsection{Heat Stress in Laboratory:}

Three leaves were selected randomly from thirteen sugar-cane genotypes for laboratory screening. The leaves were cut early in the morning from mature cane stalks between the 5th and 6th leaf from top visible dewlap. Leaf area calculated based on 3/4 of the product of length and breadth (Barnes, 1974). The leaves weighed and kept in an oven at $35^{\circ} \mathrm{C}$ for three hours. Percentage (\%) moisture loss from the excised leaves was determined using the formula of Blum (1988): ((Fresh weight -Dry weight) / Dry weight $) \times 100$.

\subsection{Phenol Contents:}

The total phenol content was measured by the method of Singleton et al. (1999). The total phenol content was determined by adding $0.5 \mathrm{ml}$ of the aqueous extract to $2.5 \mathrm{ml}, 10 \%$ Folin-Ciocalteau's reagent (v/v) and $2.0 \mathrm{ml}$ of $7.5 \%$ sodium carbonate. The reaction mixture was incubated at $45^{\circ} \mathrm{C}$ for $40 \mathrm{~min}$, and the absorbance measured at $765 \mathrm{~nm}$ in the spectrophotometer. Gallic acid used as a standard phenol. The mean of three readings used and the total phenol content expressed as milligram of gallic acid equivalents/g extract. 


\subsection{Lipid Peroxidation Estimation}

Lipid peroxidation was measured, as malondialdehyde (MDA) in the leaves was analyzed subsequent Carmak and Horst (1991). This method based on the reaction with thiobarbituric acid. Fresh leaves $(1.0 \mathrm{~g})$ were ground appropriately in $20 \mathrm{ml}$ of $0.1 \%$ trichloroacetic acid (TCA) solution and centrifuged for $10 \mathrm{~min}$ at $12000 \mathrm{~g}$. One $\mathrm{ml}$ of the supernatant was reacted with $4 \mathrm{ml}$ of $20 \%$ TCA solution comprising $0.6 \%$ thiobarbituric acid and then it was heated for 30 minutes at $95^{\circ} \mathrm{C}$ in a water bath and then right away cooled on ice. After centrifugation for 10 minutes at $12000 \mathrm{~g}$, the absorbance of the supernatant was read at 532 and $600 \mathrm{~nm}$. The contents of MDA were worked out using the extinction coefficient of $155 \mathrm{mM}^{-1} \mathrm{~cm}^{-1}$ by using the formula:

$$
\text { MDA level }(\mathrm{nmol})=\Delta(\text { A } 532 \mathrm{~nm}-\mathrm{A} 600 \mathrm{~nm}) / 1.56 \times 10^{5}
$$

The percentage increase in lipid peroxidation was calculated to find out the resistant and salt sensitive cultivars.

The level of malonyldialdehyde, as a substance that reacts with thiobarbituric acid (TBARS), was determined in homogenates of the organs and in serum according to the method of (Buege et al., 1978). The 10\% homogenates of tissues in $0.5 \mathrm{ml} \mathrm{Kcl}$ centrifuged at $10000 \mathrm{xg}$ for $30 \mathrm{~min}$. To $0.5 \mathrm{ml}$ of supernatant or $0.5 \mathrm{ml}$ of serum $0.5 \mathrm{ml}$ of $50 \%$, trichloroacetic acid added and centrifuged again, $5000 \mathrm{xg}, 5 \mathrm{~min}$. After the final centrifugation, the tubes with 0.5 $\mathrm{ml}$ of supernatant and $0.5 \mathrm{ml}$ of thiobarbituric acid covered with aluminum foil kept in a water bath at $90^{\circ} \mathrm{C}$ for 1 hour. The absorbance was read at $540 \mathrm{~nm}$ at room temperature against the blank and then concentration of thiobarbituric acid reactive substances was read from standard calibration curve, which was plotted using $1,1,3$, 3 'tetra - ethoxy propane. The resulting concentration of TBARS presented in micromoles of TBARS per dm3of serum or in nanomoles of TBARS on $\mathrm{g}$ of tissue.

\section{Results and Discussion:}

\subsection{Morphological Parameters}

Three logical clusters I, II and III based on morphological parameters. In cluster I genotypes S-2003-US-778, CPF-246, SPF-234, S-2002-US-160, CPF-237 and S-2003-US-694 are present. In cluster II CO-1148 is present and CPHS-35, S-2003-US-633, CPF-247, S-2003-US-114, SPF-238 and Rb-72 are present in cluster III. Genotype S-2003-US-778 and Rb-72 showed maximum difference due to number of leaves and leaf length. Cluster I and II connected on gene linkage 52 for of leaves, cane diameter and leaf size similarities and having dissimilarities for plant height, number of tillers, internode distance and number of internodes in Figure 5. Cluster I and II differ from cluster III for leaf length and having similarities due to plant height, leaf size, number of tillers and number of internodes therefore, I and II are connected with III on 118 gene linkage in Figure 5.
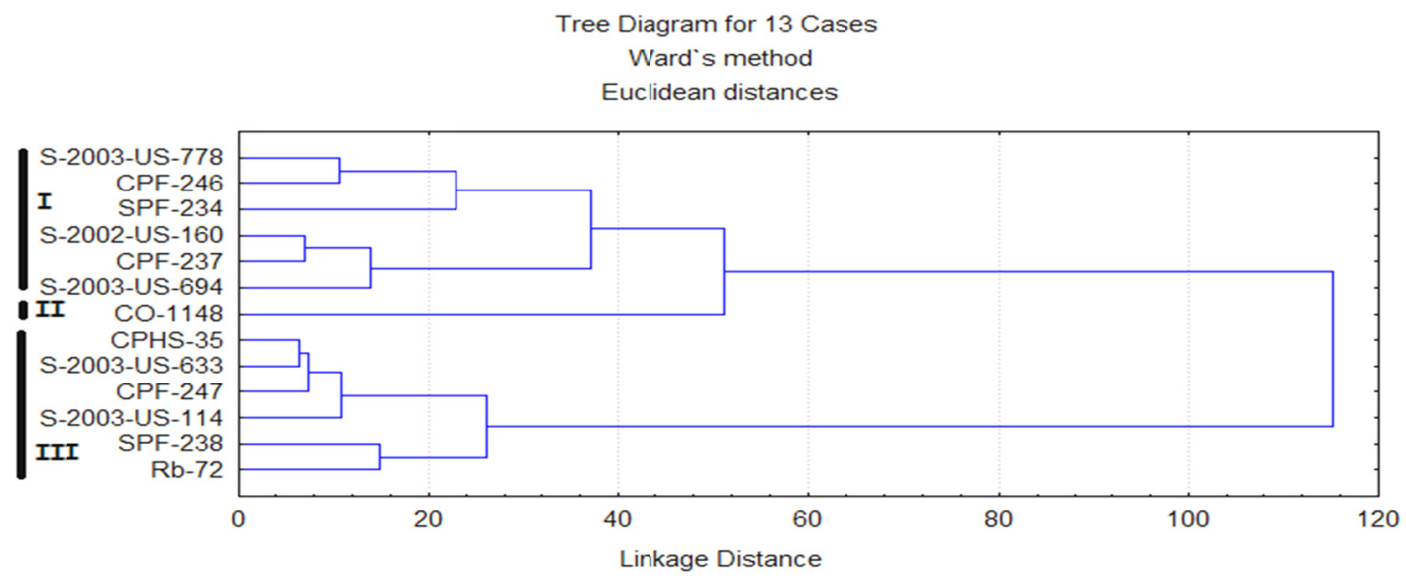

Figure 5. Dendrogramme of morphological data of thirteen sugarcane genotypes

\subsection{Total Moisture Loss}

Mean percent moisture loss from excised leaves, which is an index of moisture stress, is presented in Figure 1. Minimum observation are in genotype CPF-237 and CPHS-35 (53.4\% and 60.1\%) and Maximum moisture loss observed in CO-1148 and SPF-234 (82.5\% and 80.2\%) were also observed to lose more moisture than genotypes with smaller leaf area, as a result of the larger evaporating surface for transpiration. Although leaves of some accessions with large surface area lost much moisture when subjected to oven temperature, some accessions with 
small leaf area also exhibited similar behaviour. Barnes (1974) attributed such response to presence of many stomata and large bulliform cells in the leaves, whereas Meneses (1986) attributed it to release of electrolytes from the cells. Varieties that are least damaged by heat (i.e. low moisture loss) are likely to be tolerant to drought. This had observed also by Viqueira et al. (1984).

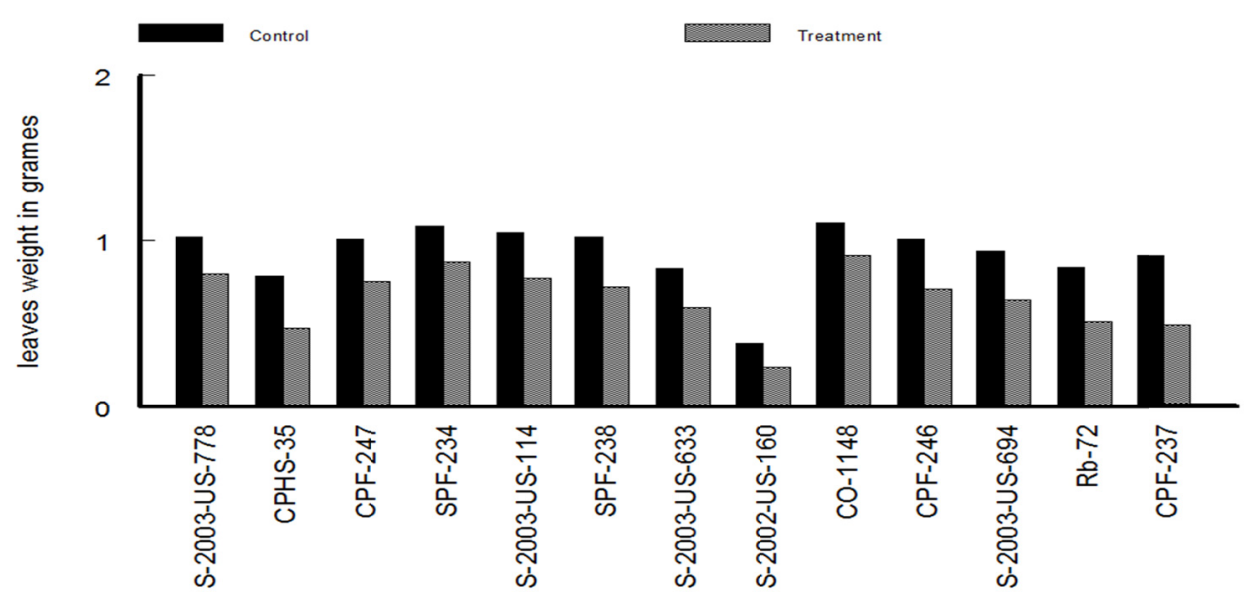

Figure 1. Result of thirteen genotypes of sugarcance (heat treatment)

\subsection{Total Phenol Compounds:}

The total phenol contents in extracts obtained from the control and heat-treated leaves of sugarcane are shown in Fig. 3. Sugarcane genotype S-2003-US-778 showed maximum values $i, e(58.78 \mathrm{mg} \mathrm{GAE} / \mathrm{g})$ at control and after treatment the absorbance have been decreased as (36.76 mg GAE/g). CPHS-35 and CPF-246 showed different results as (48.41 and $45.22 \mathrm{mg} \mathrm{GAE} / \mathrm{g}$ ) at control and gradually decrease results when stress increased, these genotypes showed results after treatment is (35.43 and $26.34 \mathrm{mg} \mathrm{GAE} / \mathrm{g}$ ). Rb-72 and CO-1148 showed lowest values i,e (36.17 and $37.5 \mathrm{mg} \mathrm{GAE} / \mathrm{g})$ at control and after treatment the values were (23.21 and 24.45 mg GAE/g) in Figure 3. In the leaves of sugarcane the major phenolics are luteolin 8-C-rhamnosylglucoside, diosmetin-8-glucoside, vitexin, orientin, tricin-7-O-neohesperidoside and tricin derivatives (Fabiana et al., 2008) which are responsible for the antioxidant activity of sugarcane. Phenol compounds present in these extracts reported to have beneficial effects on other chronic diseases such as coronary heart disease (Forester \& Waterhouse, 2009). These health effects reported to be due to antiradical and antioxidant properties of phenols in plants and plant derivatives (Lurton, 2003).

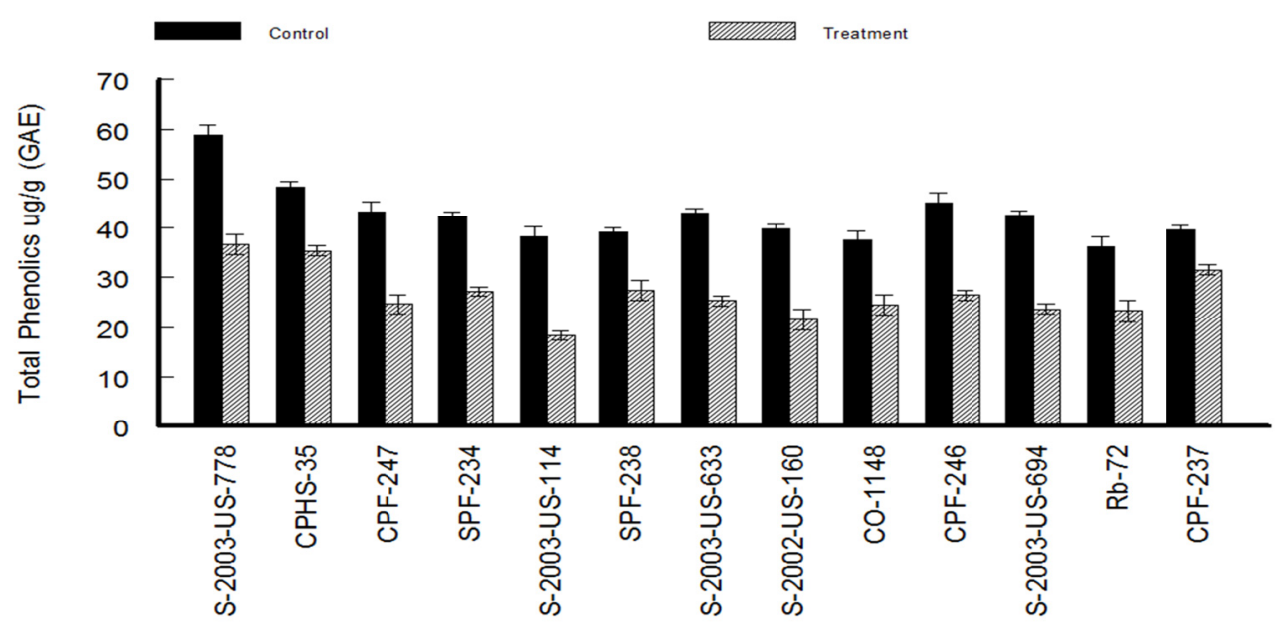

Figure 3. Thirteen genotypes of sugarcane 


\subsection{Estimation of Lipid Peroxidation:}

Lipid peroxidation (LPO) as MDA content, estimated at formative and grand growth phase of the crop, showed increasing trend over the stage as well as heat stress condition (Figure 2). Under control, CPHS-35 and S-2003-US-694 showed minimum value of 30.225 and $30.38 \mathrm{nmol}$ (malondialdehyde $\mathrm{g}^{-1}$ f.wt) respectively, and after heat treatment the values increased due stress and showed 38.9 and $40.1 \mathrm{nmol}$ (malondialdehyde $\mathrm{g}-{ }^{1}$ f.wt) respectively. CPF-246 and SPF-238 showed maximum values 60.605 and $56.265 \mathrm{nmol}$ (malondialdehyde g- ${ }^{1}$ f.wt.) respectively, after treatment the values increased and moving to 71.6 and $63.7 \mathrm{nmol}$ (malondialdehyde $\mathrm{g}-{ }^{1}$ f.wt) in Figure 2. The stress induced increase in leaf membrane damage, reduced uptake of $\mathrm{CO}_{2}$ because of closer stomatal, decreased hydrolytic enzyme activity and increased lipid peroxidation level; it may stimulate formation of AOS such as superoxide, hydrogen peroxide, and hydroxyl radicals. Among AOS, superoxide converted by SOD enzyme into $\mathrm{H}_{2} \mathrm{O}_{2}$, which is further scavenged by CAT and various peroxidases. APOX and GR also play a key role by reducing $\mathrm{H}_{2} \mathrm{O}_{2}$ to water through the Halliwell-Asada pathway (Noctor \& Foyer, 1998). Allen (1995) also reported that much of injury to plants caused by various stresses is associated with oxidative damage at cellular level such as cell membrane damage.

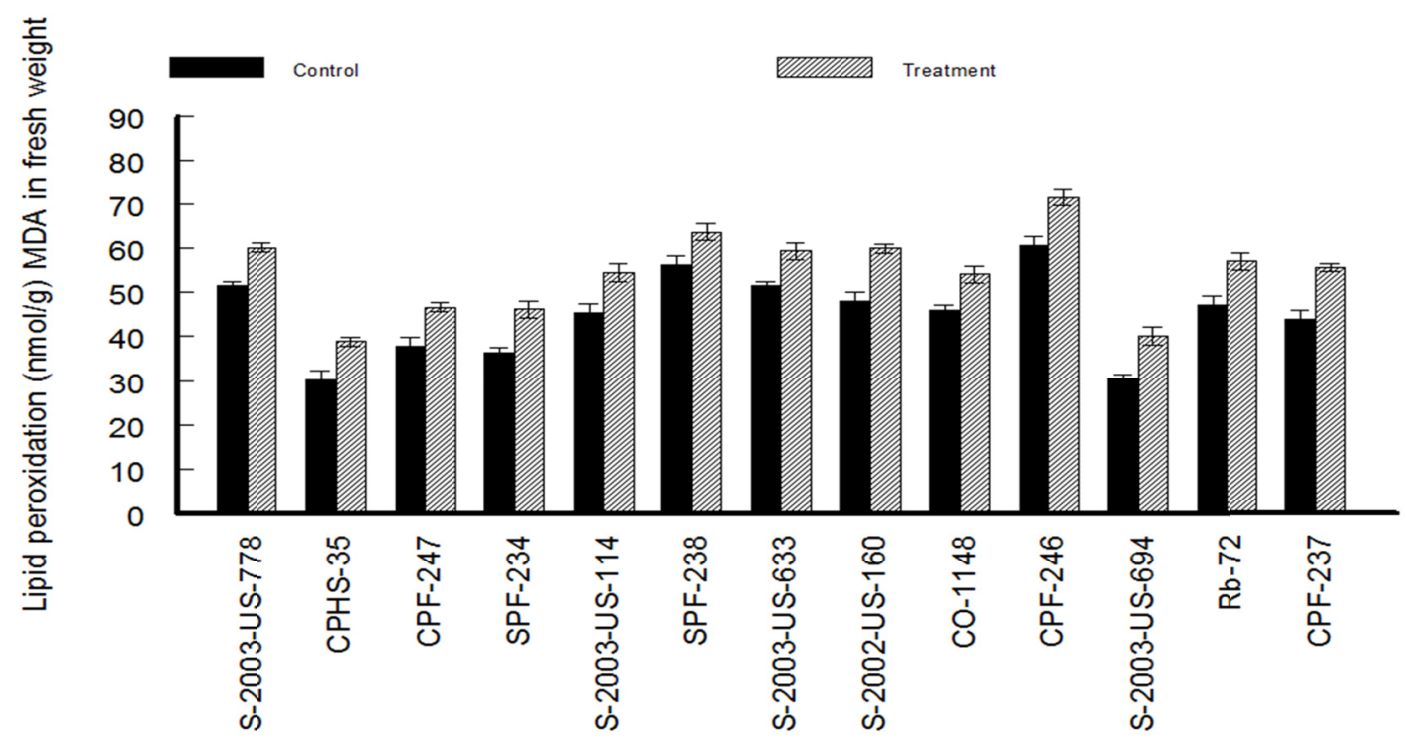

Figure 2. Thirteen genotypes of sugarcane

Cluster analyses used for the screening of thirteen genotypes of sugarcane by using MDA, Phenol and moisture loss through heat stress experiment. Cluster I having S-2003-US-778, CPHS-35, CPF-247, SPF-234 and S-2003-US-114 and in cluster II SPF-238, S-2003-US-633 and CO-1148 were present. Cluster III having S-2002-US-160, CPF-246, S-2003-US-694, Rb-72 and CPF-237. As a result, the cluster III is more heat tolerant then cluster I, main factor of heat tolerance is leaf area of cluster I having less then cluster III. CPF-237, Rb-72 and S-2003-US-694 are heat tolerant then S-2003-US-778, CPHS-35 and CPF-247 showed in Figure 4. 

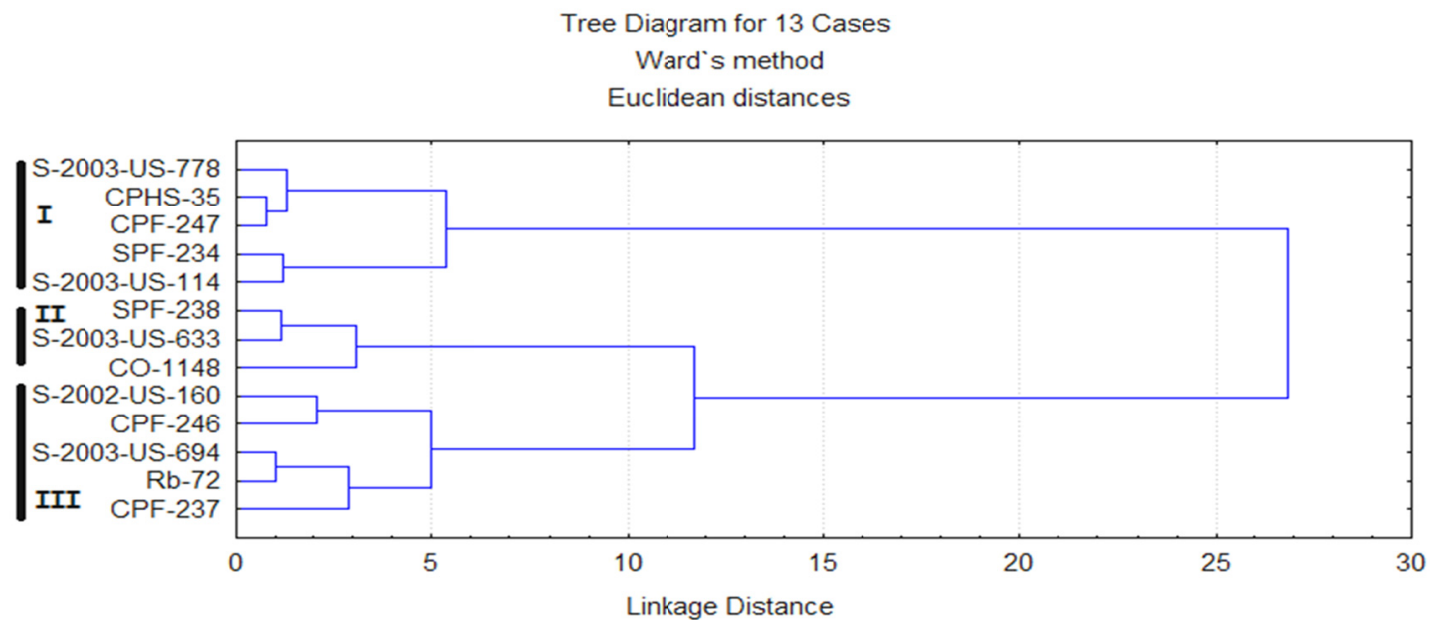

Figure 4. Dendrogramme of heat stress

\section{Conclusion}

This study gives some important clues that each genetic trait under study responded differently to temperature stress. Different Genotypes of sugarcane also showed wide variation for their response to temperature stress tolerance. Genotypic performance and sensitivity towards heat stress varied significantly. It is concluded that best genetic variability for development of heat tolerant sugarcane genotype can be created by pyramiding of genes from tolerant genotypes into high yielding cultivars. On the basis of data obtained from moisture loss, phenol content and lipid peroxidation the genotypes S-2003-US-778, S-2003-US-694, CPF-237 and Co-1148 are heat tolerant genotypes and thus can be successfully planted in warmer areas to alleviate the socioeconomic status of farmers. Further studies are in progress to show the effect of heat tolerance on antioxidant enzymes of sugarcane.

\section{References}

Abdollahi, M., Mostfalou, S., Poournoourmoohamadi, S., \& Shadnia, S. (2004). oxidative stress and cholinesterase inhibition in saliva and plasma of rats following subchronic exposure to malathion. Plant Physiol., 37, 29.

Akhtar. M., Bashir. K., Akhtar, M. E., Khan, M. Z., \& Rafiq, C. H. (2000). Effect of timing of nitrogen application on agronomic characters and nutrient contents of sugarcane (Sacharum officinarum L). Pakistan J. Biol. Sci., 3, 672-673. http://dx.doi.org/10.3923/pjbs.2000.672.673

Allen, R. D. (1995). Dissection of oxidative stress tolerance using transgenic plants. Plant Physiol., 107, 1049-1054.

Barnes, A. C. (1974). The Sugarcane (2nd ed.). London, UK: Hill Books.

Bendelow, V. W., \& Meredith, W. O. S. (1955). Reliability of prediction tests for malting quality of barley. Can. J. Agri. Sci., 35, 252-258.

Blum, A. (1988). Plant Breeding for Stress Environments (pp. 43-77). Florida, USA: CRC Press Inc.

John A. B., \& Steven, D. A. (1978). Microsomal lipid peroxidation. Methods of enzymology, $51,302$. http://dx.doi.org/10.1016/S0076-6879(78)52032-6

Carmark, I., \& Horst, J. H. (1991). Effects of aluminum on lipid peroxidation, superoxide dismutase, catalase, and peroxidase activities in root tips of soybean (Glycine max). Physiol. Plant., 83, 463-468. http://dx.doi.org/10.1111/j.1399-3054.1991.tb00121.x

Dorman, H. J. D., Kosar, M., Kahlos, K., Holm, Y., \& Hiltunen, R. (2003). Antioxidant properties and composition of aqueous extracts from Mentha species, hybrids, varieties, and cultivars. J. Agric. Food Chem., 51, 4563-4569. http://dx.doi.org/10.1021/jf034108k

Fabiana, C. V., Renata, C., Tatiana, O. D., \& Janete, H. Y. (2008). HPLC microfractionation of flavones and antioxidant (radical scavenging) activity of Saccharum officinarum L. J. Brazil Chem. Soc., 19.

Forester, S. C., \& Waterhouse, A. L. (2009). Metabolites are key to understanding health effects of wine polyphenolics. J. Nutr., 138, 1824S-1831S. http://dx.doi.org/10.3945/jn.109.107664 
Iftikhar, T., Babar, L. K., Zahoor, S., \& Khan, N. G. (2010). "Best Irrigation Management Practices In Cotton". Pak. J. Bot., 42(5), 3023-3028.

Lotti, M. (2001). Clinical toxicology of anticholinesterase agents in humans. Academic Press, USA: Handbook of Pesticide Toxicology.

Lurton, L. (2003). Grape polyphenols: New powerful health ingredients.Innov. Food Technol., 18, 28-30.

Mates, J. M., Perez-Gomez, C., \& De Catro, I. N. (1999). Antioxidant enzymes and human diseases. Clin. Biochem., 32, 595. http://dx.doi.org/10.1016/S0009-9120(99)00075-2

Meneses, R. S. (1986). Assessment of drought resistance in sugarcane varieties through the determination of the release of electrolytes. Plant Breeding Abstracts, 56(11), 1057.

Moore, P. H. (1987). Physiological basis for varietal improvement in sugarcane. In Proceedings of the International Symposium on Sugarcane Varietal Improvement (pp. 19-56). Sugarcane Breeding Institute, Coimbatore, India, 3-7 September 1987.

Nasir, N. M. (2006). Better management practices for cotton and sugar cane (p. 117). WWF-Pakistan, Ferozepur Road, Lahore - 54600, Pakistan.

Noctor, G., \& Foyer, C. H. (1998). Ascorbate and glutathione: keeping active oxygen under control.Annu. Rev. Plant Physiol. Plant Mol. Bio., 49, 249-279. http://dx.doi.org/10.1146/annurev.arplant.49.1.249

Rehman, M. S. (2009). Pakistan Sugar Annual 2009. USDA Foreign Agric. Serv.

Sharma, Y., Bashir, S., Irshad, M., Gupta, S. D., \& Dogra, T. D. (2005). Effects of acute dimethoate administration on antioxidant status of liver and brain of experimental rats. Toxicology, 5, 49.

Triantaphyllou, K., Blekas, G., \& Boskou. (2001). Antioxidative properties of water extracts obtained from herbs of thespeciesLamiaceae. Int. J. Food Sci. Nutr., 52, 313-317.

Viqueira, L, Gomez, L, \& Rodriguez, C. R. (1984). Tolerance of high temperature in sugarcane. II Estimation of the drought tolerance of different varieties. Plant Breeding Abstracts., 54, 335.

Yagi, K. (1987). Lipid peroxides in human disease. Chem. Phys. Lipids., 45, 337.

\section{Copyrights}

Copyright for this article is retained by the author(s), with first publication rights granted to the journal.

This is an open-access article distributed under the terms and conditions of the Creative Commons Attribution license (http://creativecommons.org/licenses/by/3.0/). 